\title{
Empirical Modeling of Kinetics of Transesterification and Cold Flow Properties of Used Soya Oil Biodiesel
}

\author{
Umeuzuegbu J.C. \\ Department of Chemical Engineering, Faculty of Engineering, \\ Chukwuemeka Odumegwu Ojukwu University, Anambra State, Nigeria
}

\begin{abstract}
This research work focused on empirical modeling of kinetics of transesterification and cold flow properties of homogeneous catalyzed used soya oil fatty acid methyl ester (USOFAME]. Used soya oil (USO) was prepared by frying food (yam, potato plantain etc) with virgin soya oil for a total of 72 hours [1].The oil was characterized based on American Society for Testing and Materials (ASTM) method. The fatty acid profile of used soya oil was analyzed using gas chromatography mass spectroscopy (GC MS) while the functional groups of the triglyceride were determined using Fourier transform infrared spectroscopy (FTIR). The oil was pretreated to reduce the free fatty acid level below $1 \%$ and then transesterified using methanol in the presence of sodium hydroxide catalyst. The fuel properties of the USOFAME produced were determined based on ASTM standards. Kinetic experiments were conducted in batches at different temperatures of $450 \mathrm{C}, 550 \mathrm{C}$ and $650 \mathrm{C}$. Application of rate laws to the three-step reversible reaction scheme of transesterification yielded a series of ordinary differential equations (ODEs) solved with polymath 5.1 software to give the forward and reverse rate constants k1,k2, k3, k4, k5 and $\mathrm{k} 6$ from which the rate limiting step (RLS) and activation energy $(\Delta \mathrm{E})$ were derived. The cold flow properties, cloud point $(\mathrm{CP})$, cold filter plugging point (CFPP) and pour point (PP) were determined experimentally for different blends of biodiesel with \#2 diesel, at a percentage volume ratio of biodiesel to diesel 0 , 20, 40, 60, 80, and 100. The values obtained for CP, CFPP, and PP were plotted against the biodiesel fraction in the blends. Least square regression of the data of the plots were tested on linear, quadratic and polynomial models using Microsoft excel. The fuel properties of the USOFAME which is within the ASTM standards were determined as acid value $0.4 \mathrm{mgKOH} / \mathrm{g}$, density $863 \mathrm{~mm} 2 / \mathrm{s}$, kinematic viscosity $4.60 \mathrm{~mm} 2 / \mathrm{s}$, flash point $1620 \mathrm{C}$, cetane number 61.00 , calorific value $40.06 \mathrm{MJ} / \mathrm{Kg}$, pour point $-40 \mathrm{C}$, cold filter plugging point $-2.80 \mathrm{C}$, cloud point $00 \mathrm{C}$, iodine value $30.60 \mathrm{gI} / 100 \mathrm{~g}$. Kinetic modeling of transesterification of USOFAME shows that the forward rate constants $\mathrm{K} 1, \mathrm{~K} 2$, and $\mathrm{K} 3$ are greater than those of the reverse reaction $\mathrm{k} 2, \mathrm{k} 4, \mathrm{k} 6$, imply that the forward reaction dominates while the reverse reaction could be neglected. The rate constant $\mathrm{k} 1$ for triglyceride conversion to diglyceride is the least among the forward rate constants at 450C, 550C and650C imply that this step is the rate limiting step (RLS). Application of least square regression analysis of Microsoft excel on the data of variation of cold flow properties with biodiesel fraction, revealed polynomial model to be the best fitting equation.
\end{abstract}

\section{Keywords}

Characterization, cold flow properties, kinetic modeling, transesterification, used soya oil fatty acid methyl ester.

\section{INTRODUCTION}

The soaring demand for energy and industrial raw materials from crude oil has hastened the depletion of its reserves, coupled with the adverse environmental impact and the unstable international market has compelled researchers to look for alternative fuel and raw material sources to fill the gap. Oils and fat from plants and animals has proved alternative sources as they are readily converted to biodiesel by suitable methods. Among the various options investigated, for fossil oil replacement, biodiesel produced from vegetable oil and other sources has been universally recognized as the foremost contender for exhaust emission reduction [2]. Burning of fossil fuel results in environmental pollution from emission of green house gases, including sulphur oxides (SOx), nitrogen oxides (NOx), carbon monoxide (CO), hydrocarbon ( $\mathrm{HC})$, and methane [3]. Biodiesel is a mono-alkyl ester of long chain fatty acid that posses characteristics similar to diesel with additional advantages of high lubricity, high cetane number, being biodegradable and environmentally friendly [4]. The bulk of biodiesel presently produced worldwide come from edible oil feed stock. The researcher [5] has reported that 95\% of renewable resources used for biodiesel production come from edible vegetable oil, and this has been envisaged to have serious implication on food availability and the cost of biodiesel. As a result, concerted effort has being geared towards the production of biodiesel from non-edible oils and used cooking oils (UCO) feed stock. Used cooking oils have many disposal problems like water and soil pollution, human health concern, and disturbance to aquatic ecosystem [6]. Rather than its disposal that is harmful to the environment, it can be used as cost-effective feedstock for production of biodiesel. Biodiesel is produced by the reaction of fat with monohydric alcohol. Various processes have been adopted for biodiesel production from vegetable oil and animal fat, namely; micro-emulsion with alcohol, catalytic cracking, pyrolysis and transesterification [7], [8], [9], [10]. Among these methods, transesterification is the key and the most important process for production of a cleaner and environmentally safe biodiesel [11], [12]. Worldwide, biodiesel production is mainly from edible oils such as soybean, sunflower canola, palm oil etc. Utilization of edible oils as feedstock for biodiesel production poses a lot of concerns as this practice competes with food supply leading to high cost of edible vegetable oil, and consequently results in relative increase in biodiesel production 


\section{Empirical Modeling of Kinetics of Transesterification and Cold Flow Properties of Used Soya Oil Biodiesel}

cost. Therefore, concerted research efforts are geared towards evaluating non-edible oils and waste cooking oil (WCO) or used cooking oil (UCO) as suitable feedstock. Used cooking oil or used oil for short refers to used vegetable oil obtained from cooking or frying of food. Repeated frying for preparation of food make such an oil unsuitable for consumption due to high free fatty acid content [12]. In order to minimize the market prize of edible oil and stem the contentious debate on the ill effect of use of edible oil for biodiesel production, research is now geared towards the use of UCO feedstock [13], [14], [15]. In order to carry out the research on a particular used oil (soya oil), used soya oil was prepared by frying foods (yam, potato plantain etc) in a virgin soya oil for a total of 72 hours [1]. The resulting used soya oil was then synthesized into biodiesel of which the kinetics of transesterification and cold flow temperature operability were modeled. The kinetics of transesterification of biodiesel has in the past been based on the stoichiometry of the reaction which assumed a single reaction step. However transesterification involves a series of reaction steps for conversion of triglyceride to biodiesel. The research work on kinetics focused on modeling the kinetics of homogeneous catalyzed transesterification of used soya oil based on appropriate reaction mechanism of multiple steps and empirical results of kinetic experiments. Researchers [16] and [17] have predicted cold flow properties of biodiesel based on the total unsaturated fatty acid methyl ester and on the biodiesel fraction in the blend. As the amount of unsaturated fatty acid and their chain length in the biodiesel is directly related to the biodiesel fraction in the blend, the cold flow properties of the biodiesel blend can be correlated with biodiesel fraction. The research work on cold flow properties is focused on modeling of the temperature operability of the USOFAME based on the biodiesel fraction in the blend.

\section{MATERIALS AND METHODS}

\subsection{Materials}

Used soya oil, reagents, glass wares, equipments including gas chromatography mass spectrometer (GC-MS), Fourier transform infrared spectroscopy (FTIR), viscometer, magnetic hot plate, water bath, polymath 5.1 software etc.

\subsubsection{Preparation of used soya oil}

!0 liters out of 20 liters of crude soy oil purchased from Ogboete main market Enugu, in Enugu state was introduced into 20 liter steel pot. The oil was heated using gas cooker for frying foods (yam, plantain and potatoes) for a duration of 72hours ( 8 hours per day for 9 days) and then cooled to make waste or used cooking oil [1]. A test of the acid values showed much increase in the acid value from $0.23 \mathrm{mg} / \mathrm{g}$ for the pure oil to $4.60 \mathrm{mg} / \mathrm{g}$ for the used oil.

\subsubsection{Characterization of used soya oil}

The physiochemical properties of the used soya oil was characterized based on American Society for Testing Materials, ASTM 6751 (1973) method. Analytical equipments, GC- MS (QP2010 plus Shimadzu, Japan) and FTIR (M530 Bulk scientific FTIR ) were used to determine the fatty acid profile and the functional groups of the oil respectively.

\subsubsection{Pretreatment of the used soya oil}

As the free fatty acid of the used soya oil exceeded the tolerable limit of $1 \%$ for transesterification of oil using alkaline catalyst, the oil was first of all pretreated with methanol in the presence of sulphuric acid to reduce the free fatty acid below $1 \%$. The pretreatment or esterification of the oil involve heating the oil on a heating mantle to $1100 \mathrm{C}$ for 10 minutes to drive off available moisture in the oil. This was followed by cooling the oil to $600 \mathrm{C}$ in a water bath. The oil was then introduced into a $500 \mathrm{ml}$ round bottomed flask and then the mixture of methanol of $60 \% \mathrm{w} / \mathrm{w}$ of oil and sulphuric acid 7\% w/w of oil was added. Into the middle arm of the flask was fitted a reflux condenser, and a thermometer into the sample through the side arm. The setup was heated using a magnetic heating mantle to a constant temperature of $600 \mathrm{Cfor} 1$ hour at an agitation speed of $350 \mathrm{rpm}$.when the heated and refluxed content of the flask was transferred into $250 \mathrm{ml}$ separating funnels. After settling, the funnel content separates into three layers, water at the bottom, pretreated oil in the middle and methanol at the upper layer. The three layers were carefully tapped off separately, water first, followed by the oil and finally methanol. Hot distilled water was poured into the oil in a separating funnel, shaken and allowed to stand when it separated into water and oil layers below and above the funnel respectively. The water layer was tapped off from the separating funnel and the pre-treated oil was poured into $250 \mathrm{ml}$ beakers and dried carefully in an oven regulated at a temperature of $1050 \mathrm{C}$ until the residual water evaporated completely. After this process, the pre-treated oil was made ready for transesterification [18].

\subsubsection{USOFAME Production and purification}

The esterified oil was transesterified using methanol and sodium hydroxide catalyst. A $500 \mathrm{ml}$ three-necked round bottomed flask fitted with a condenser on the middle arm, a thermometer and sample outlet on the side arms respectively served as the reactor. The heating system consists of an electromagnetic hot plate which heats the reactor and rotates the metal knob in the reactor through an electromagnetic field. Specified quantity of the oil sample was introduced into the flask and the flask content heated to the temperature established for the reaction. Then methanol and the catalyst sodium hydroxide $(\mathrm{NaOH})$ mixture was added in the amount established for the reaction, and the stirrer switched on at a specified speed, taking this moment as zero time of the reaction. The reaction mixture was vigorously stirred and refluxed for the required reaction time. At the end of methanolysis, the transesterfied product was made to stand for a day in separating funnels where it separates into the upper biodiesel layer and the lower glycerol layer. The lower glycerol layer was tapped off first followed by the upper biodiesel layer. After transesterification, the upper ester layer may contain traces of methanol and glycerol. The remaining un-reacted methanol has safety risk and might corrode engine components, and glycerin within the biodiesel may lessen the fuel lubricity and cause injector coking and other deposits [19]. Such trace of methanol is soluble in water and is therefore removed by wet washing. The methyl ester or biodiesel layer was gently washed with hot distilled water in the ratio of 3:1 water to methyl ester. The methyl ester was gently washed to prevent its loss due to formation of emulsion that results in complete phase separation [20].. The washed biodiesel was dried by heating at $1050 \mathrm{C}$ on a laboratory hot plate until all residual water molecules is evaporated. This conforms with the findings of [21]. The percentage biodiesel yield is given by the expression of equation (1)

$$
\begin{aligned}
\% \text { biodiesel yield } & =\text { Volume of biodiesel produced } \\
& \div \text { volume of oil used } x 100
\end{aligned}
$$




\subsection{Determination of fuel properties of USOFAME}

The properties of the biodiesel fuel were characterized based on ASTM standards. The properties characterized include density, viscosity, iodine value, saponification value, cetane number, acid value, free fatty acid, calorific value, flash point, cloud point, pour point and cold filter plugging point.

\subsection{Kinetics of transesterification of USO}

The kinetics of homogeneous transesterification of used soya oil using methanol and $\mathrm{NaOH}$ catalyst was studied. This involved kinetic modeling and kinetic experiment on transesterification of used soya oil. Transesterification of triglyceride (TG) consist of series of reversible reaction steps involving conversion of triglyceride to diglyceride (DG), diglyceride to monoglyceride (MG) and monoglyceride to biodiesel (BD) and a byproduct glycerol (GL) using methanol (MN) and $\mathrm{NaOH}$ catalyst as shown in equations 2 to 4 . However, the kinetics of such reactions is first order with respect to the reacting component's concentration as shown in equations 2 to 4 [1]. Applying the rate law to equations 2 to 4 yielded a system of ordinary differential equations (ODE's) 6 to 25. Kinetic experiments were carried out in batches at different temperatures of 450C, 550C and $650 \mathrm{C}$. Samples were withdrawn from the reaction mixture of the kinetic experiments at 15 minutes interval from 0 to 90 minutes and the concentration of the TG, DG, MG, BD,MN, and GL of the samples were determined using GC-MS. The concentration of the TG, DG, MG, BD, MN and GL denoted by [TG], [DG], $[\mathrm{MG}],[\mathrm{BD}],[\mathrm{MN}]$ and $[\mathrm{GL}]$ respectively were inserted into the ODE's and then solved using polymath 5.1 software to obtain the rate constants $\mathrm{k} 1$ to $\mathrm{k} 6$ at different temperatures of $450 \mathrm{C}$, $550 \mathrm{C}$ and $650 \mathrm{C}$.

$\mathrm{TG}+\mathrm{ROH} \underset{k_{2}}{\stackrel{k_{1}}{\rightarrow}} \mathrm{DG}+\mathrm{BD}(2)$

$\mathrm{DG}+\mathrm{ROH} \underset{k_{4}}{\stackrel{k_{3}}{\rightarrow}} \mathrm{MG}+\mathrm{BD}(3)$

$\mathrm{MG}+\mathrm{ROH} \underset{k_{6}}{\stackrel{k_{5}}{\rightarrow}} \mathrm{BD}+\mathrm{GL}(4)$

where $k_{1}, k_{3}$ and $k_{5}$ are the forward rate constants while $k_{2}, k_{4}$ and $k_{6}$ are the reverse rate constants. Each of the three steps consumes 1 mole of alcohol to produces 1 mole of ester and the overall equation can be represented by equation (5) below.

$\mathrm{TG}+3 \mathrm{ROH} \underset{k_{b}}{\stackrel{k_{f}}{\rightarrow}} 3 \mathrm{BD}+\mathrm{GL}(5)$

where, $\mathrm{kf}=$ rate constant for forward reaction, $\mathrm{kb}=$ rate constant for backward reaction

Equations (2) to (4) yielded 6 elementary reactions, unto which the application of rate law generate a system of ordinary differential equations (6) to (25). The solution of equations (6). (10), (14), (19), (20) and (25) using polymath 5.1 gave the values of the rate constants k1 to k6

$r_{T G}=-\frac{d[T G]}{d t}=k_{1}[\mathrm{TG}][\mathrm{ROH}]-k_{2}[\mathrm{DG}][\mathrm{BD}](6)$

Similarly, other rate expressions were also derived in the same manner as follows:

$r_{D G}=r_{D G 1}+r_{D G 2} \quad$ (7)

$r_{D G 1}=-\frac{d[D G]}{d t}=k_{2}[\mathrm{DG}][\mathrm{BD}]-\mathrm{k} 1 \quad[\mathrm{TG}][\mathrm{ROH}](8)$

$r_{D G 2}=-\frac{d[D G]}{d t}=k_{3}[\mathrm{DG}][\mathrm{ROH}]-\mathrm{k} 4[\mathrm{MG}][\mathrm{BD}]$ (9)

$r_{D G}=k_{3}[\mathrm{DG}][\mathrm{ROH}]-\mathrm{k} 1 \quad[\mathrm{TG}][\mathrm{ROH}]+k_{2}[\mathrm{DG}][\mathrm{BD}]-\mathrm{k} 4$

[MG][BD] (10)

$r_{M G}=r_{M G 1}+r_{M G 2}$

$r_{M G 1}=k_{4}[\mathrm{MG}][\mathrm{BD}]-k_{3}[\mathrm{DG}][\mathrm{ROH}]$

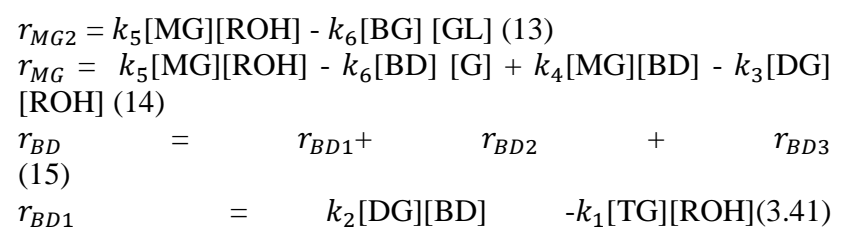

(16)

$r_{B D 2}=k_{4}[\mathrm{MG}][\mathrm{BD}]-k_{3}[\mathrm{DG}][\mathrm{ROH}]$

$r_{B D 3}=k_{6}[\mathrm{BD}][\mathrm{GL}]-k_{5}[\mathrm{MG}][\mathrm{ROH}]$

$r_{B D}=k_{2}[\mathrm{DG}][\mathrm{BD}] \quad-k_{1}[\mathrm{TG}][\mathrm{ROH}]+k_{4}[\mathrm{MG}][\mathrm{BD}]$

$k_{3}[\mathrm{DG}][\mathrm{ROH}]+k_{6}[\mathrm{BD}][\mathrm{G}]-k_{5}[\mathrm{MG}][\mathrm{ROH}]$

(19)

$r_{G L}=-k_{5}[\mathrm{MG}][\mathrm{ROH}]+k_{6}[\mathrm{BD}][\mathrm{G}]$

$r_{\mathrm{ROH}}=r_{\mathrm{ROH} 1}+r_{\mathrm{ROH} 2}+r_{\mathrm{ROH} 3}$

$r_{R O H 1}=k_{1}[\mathrm{ROH}][\mathrm{TG}]-k_{2}[\mathrm{DG}][\mathrm{BD}]$

$r_{\mathrm{ROH} 2}=k_{3}[\mathrm{ROH}][\mathrm{DG}]-k_{4}[\mathrm{MG}][\mathrm{BD}]$

$r_{\mathrm{ROH} 3}=k_{5}[\mathrm{ROH}][\mathrm{MG}]-k_{6}[\mathrm{G}][\mathrm{BD}]$

$r_{R O H}=k_{1}[\mathrm{ROH}][\mathrm{TG}]-k_{2}[\mathrm{DG}][\mathrm{BD}]+k_{3}[\mathrm{ROH}][\mathrm{DG}]-$

$k_{4}[\mathrm{MG}][\mathrm{BD}]+k_{5}[\mathrm{ROH}][\mathrm{MG}]-k_{6}[\mathrm{G}][\mathrm{BD}](25)$

$\mathrm{K}=\mathrm{Ae}-\mathrm{E} / \mathrm{RT}$ (26)

$\operatorname{lnk}=\ln \mathrm{A}-\mathrm{E} / \mathrm{RT} \quad$ (27)

Temperature dependency of rate constant

The dependency of rate constant on temperature is well represented by Arrhenius equation (26). Taking the log of equation (26) gave equation (27). From equation (27) the plot of lnk versus $1 / \mathrm{T}$ gave the slope $-\mathrm{E} / \mathrm{R}$ from which the activation energy ( $E$ ) was obtained. where $A$ is the frequency factor, $R$ is the universal gas constant(Jmol-1K-1) and $\mathrm{E}$ is the activation energy $(\mathrm{Jmol}-1)$. The plots of lnk versus $1 / \mathrm{T}$ are given in figures 3 to 8 , and the values of the activation energy are given in table 4.

\subsection{Modeling the effect of biodiesel blending on cold flow properties}

Researchers [16], and [17] have correlated cold flow properties of biodiesel as a function of total unsaturated fatty acid methyl ester and as a function of biodiesel fraction in the blend respectively. Since the degree of un-saturation of fatty acid methyl ester is directly related to the biodiesel fraction in the blend, the cold flow properties, cloud point (CP), pour point (PP) and cold filter plugging point (CFPP) in this work were predicted based on the biodiesel fraction in the blend. Polynomial model has been employed in the past for prediction of cold flow properties as a function of biodiesel fraction. Here, apart from polynomial model, other predicting model equations including linear and exponential models were evaluated in order to obtain the best equation of fit. The fitting equations are:
$\mathrm{Y}=\mathrm{a}+\mathrm{bx}$
(1)
$\mathrm{Y}=$ cedx

$\mathrm{Y}=\mathrm{f}+\mathrm{gx}+\mathrm{hx} 2$

where Y's are the dependent variable or response (CP, CFPP, $\mathrm{PP})$ and $\mathrm{x}$ the independent variable (biodiesel fraction in the blends). a, b, c, d, f, g and h are model correlation coefficients.

\subsection{Blending of the used soya oil biodiesel with petro-diesel.}

The used soya oil biodiesel was blended with \#2 diesel oil on a percentage volume ratio of biodiesel to diesel ; 0, 20, 40, 60, 80 and 100 designated as B0, B20, B40, B60, B80 and B100 respectively. Direct blending of the required volumes of the biodiesel and diesel was carried out in conical flasks with continuous stirring to achieve uniformity of mixing. 


\section{RESULTS AND DISCUSSION}

\subsection{Characteristics of Used Soya Oil}

The summary of the characteristics of used soya oil are presented in the Table1, From the table, it is seen that the free fatty of the used soya oil $(2.10 \%)$ is greater than $1 \%$, and therefore need be reduced below $1 \%$ for effective transesterification with alkali catalyst. Alkali catalysis of oils of high free fatty acid has high tendency for soap formation, reduction in biodiesel formation as a result of inhibition of the separation of esters from glycerol [22]. This accounts for pretreatment of the oil before esterification with alkali catalyst. The kinematic viscosity measures the flow resistance of the fuel while the density of the oil plays a role in its measurement since this is determined volumetrically. The kinematic viscosity and the density of the oil $\left(47.78 \mathrm{~mm}^{2} \mathrm{~s}^{-1}\right.$ and $\left.962 \mathrm{~kg} / \mathrm{m}^{3}\right)$ are higher than those of the biodiesel produced from it $\left(4.60 \mathrm{~mm}^{2} \mathrm{~s}^{-1}\right.$ and $\left.863 \mathrm{~kg} / \mathrm{m}^{3}\right)$ and even much higher than that of diesel $\left(4.2 \mathrm{~mm}^{2} \mathrm{~s}^{-1}\right.$ and $835 \mathrm{~kg} / \mathrm{m}^{3}$ ). High density and viscosity make atomization of the oil in internal combustion engine difficult and has been associated with increase in engine deposits, hence they cannot be used directly as bio-fuel [23]. The determined density of the oil $962 \mathrm{~kg} / \mathrm{m}^{3}$ is in agreement with the literature findings of [20] but at variance with [24] and [25].

Iodine value, a measure of degree of un-saturation of the oil was obtained for USO as $75.4 \mathrm{gI}_{2} / \mathrm{g}$ is below $100 \mathrm{gI}_{2} / 100 \mathrm{~g}$ oil, indicative of the oil being nondrying and therefore suitable for biodiesel production. High iodine value of oil corresponds to high degree of un-saturation of the fatty acid in the triglyceride. If heated, such oil is prone to thermal oxidation and polymerization of the triglyceride causing formation of deposits. The calorific value of used soya oil like that of any oil is relatively lower than that of diesel. The cloud and pour point of $5^{0} \mathrm{C}$ and $-0.5^{\circ} \mathrm{C}$ respectively determined for the used soya oil are relatively low but not to the extent of being suitable for operation and handling during cold weather especially in cold climates. Peroxide value, an index of rancidity obtained as $9.5 \mathrm{meq} / \mathrm{kg}$ was high and indicative of poor resistance of the oil to peroxidation during heating, storage and handling. The saponification value determined as 198.5 is in agreement with literature findings of [26] and [27].
Table 1: Physiochemical properties of USO oil

\begin{tabular}{|c|c|c|}
\hline Properties & Unit & USO \\
\hline Acid value & $\mathrm{mgKOH} / \mathrm{g}$ & 4.20 \\
\hline Free fatty acid & $\%$ & 2.10 \\
\hline Saponification value & $\mathrm{mgKOH} / \mathrm{g}$ & 187.5 \\
\hline Iodine value & (gI2/100g oil) & 75.4 \\
\hline Peroxide value & $\mathrm{meq} / \mathrm{kg}$ & 9.5 \\
\hline Kinematic viscosity & $\mathrm{mm} 2 \mathrm{~s}-1$ @ 400C & 47.78 \\
\hline Fire point & 0C & 280 \\
\hline Flash point & 0C & 180 \\
\hline Cloud point & 0C & 5 \\
\hline Pour point & 0C & -5 \\
\hline Refractive index & & 0.4112 \\
\hline Specific gravity & & 0.962 \\
\hline Moisture content & $\%$ & 0.2 \\
\hline Density & $\mathrm{Kg} / \mathrm{m} 3$ & 962 \\
\hline Calorific value & $\mathrm{MJ} / \mathrm{kg}$ & 34.20 \\
\hline
\end{tabular}

\subsection{The Fatty Acid Profile of Used Soya Oil}

The fatty acid profile of used soya oil was determined using gas chromatography mass spectrometry (GC-MS). Figure1 shows the GC-MS spectra of used soya oil. The summary of fatty acid composition of used soya oil is shown in Table 2. Used soya oil consist of $32.64 \%$ of saturated acids (myristic acid, stearic acid, palmitic acid and arachidic acid ) and $53.67 \%$ unsaturated acids (oleic acid, linoleic acid, linolenic acid and lignoceric acid ). The dominant monounsaturated fatty acid of the oil is oleic acid, which accounted for $50.5 \%$ of the total fatty acid content, hence, the oil belongs to oleic acid category [28]. The oleic acid content of used soya oil is comparatively higher than $7-40 \%$ reported for coconut oil, palm oil and cottonseed oil [29], [30]. This shows that used soya oil is highly unsaturated triglycerides. Nevertheless, the fatty acid components of the used soya oil were found to be consistent with the fatty acids present in typical oils used for producing biodiesel.

\subsection{Fourier Transform Infrared (FT-IR) Spectra Analysis of Used Soya Oil}

The FTIR spectrum analysis of used soya oil was determined as shown in Figure 2. From the result, obvious peaks of note were recorded . The region $723.8 \mathrm{~cm}-1$ ( $679.61 \mathrm{~cm}-1-886.65 \mathrm{~cm}-1)$ indicate the presence of $=\mathrm{C}-\mathrm{H}($ alkenes $)$ functional groups. They possess bending type of vibrations appearing at low energy and frequency region in the spectrum and they are all double bounded. They are attributed to olefins (alkenes) functional groups and are unsaturated. The characteristics peak found in the region $1114.5 \mathrm{~cm}-1(1050.15-1297.23 \mathrm{~cm}-1)$ indicate stretching vibrations of $\mathrm{C}-\mathrm{O}$ and $\mathrm{C}-\mathrm{O}-\mathrm{C}$.They can also indicate the bending vibration of $\mathrm{O}-\mathrm{CH} 3$ in the spectrum [31], [32]. The band region of $1375 \mathrm{~cm}-1$ can be ascribed to the bending vibration of $\mathrm{C}-\mathrm{H}$ methyl groups, while the band at $1401 \mathrm{~cm}-1$ (1400-1800 cm-1 ) is ascribed to $\mathrm{C}=\mathrm{C}$ bending vibrations [33] The peaks at $2855.75 \mathrm{~cm}-1$ and $2922 \mathrm{~cm}-1$ indicate symmetric and asymmetric stretching vibrations of $\mathrm{C}-\mathrm{H}$ alkane groups respectively. They could be methyl $(\mathrm{CH} 3)$ or methylene groups 


\section{Empirical Modeling of Kinetics of Transesterification and Cold Flow Properties of Used Soya Oil Biodiesel}

and they require high energy to cause stretching vibrations within their bond when compared to the ordinary $\mathrm{C}-\mathrm{H}$ bending vibrations of alkene groups detected at low energy and frequency region [34], [35]. The peak at $3000 \mathrm{~cm}-1$ is attributed to the stretching vibration of $=\mathrm{C}-\mathrm{H}$ alkene groups. They are detected above wave number $3000 \mathrm{~cm}-1$ in the spectrum compared to corresponding alkane $\mathrm{C}-\mathrm{H}$ stretching groups detected

\section{Scan 1972 (75.332 min): S14.Didata.ms}

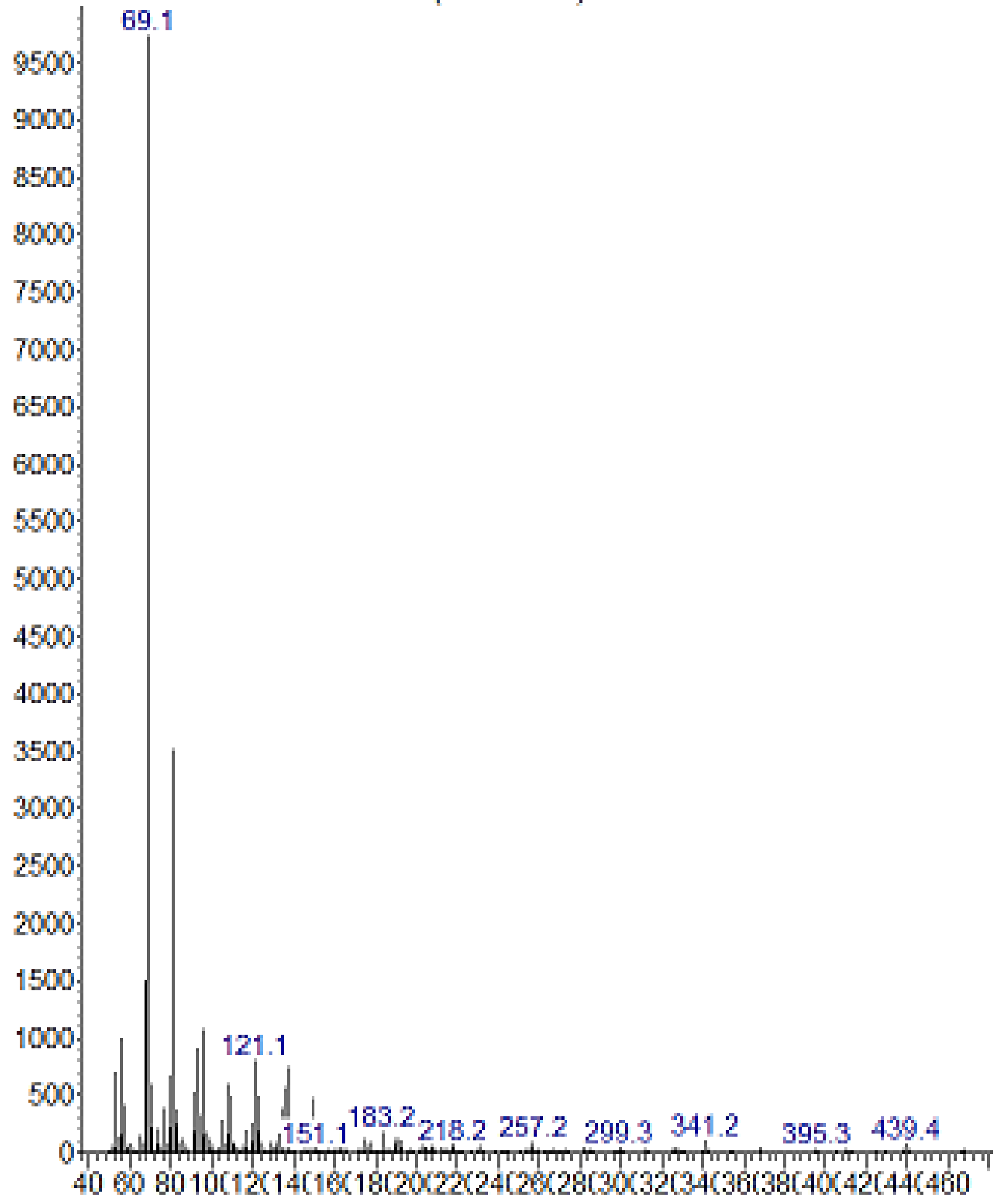

Figure 1: GC-MS Spectra of used soya oil 


\section{Empirical Modeling of Kinetics of Transesterification and Cold Flow Properties of Used Soya Oil Biodiesel}

Table 2: Summary of fatty acid composition of used soya oil.

\begin{tabular}{|l|l|l|l|}
\hline Fatty Acid & Structure & $\begin{array}{l}\text { Composition } \\
(\%)\end{array}$ & $\begin{array}{l}\text { Molecular weight } \\
(\mathrm{g} / \mathrm{mol})\end{array}$ \\
\hline Myristic acid & $\mathrm{C} 14: 0$ & 0.85 & 228.30 \\
\hline Oleic acid & $\mathrm{C} 18: 1$ & 50.5 & 282.465 \\
\hline Stearic acid & $\mathrm{C} 18: 0$ & 10.56 & 284.48 \\
\hline Palmitic acid & $\mathrm{C} 16: 0$ & 20.56 & 256.4 \\
\hline Arachidic acid & $\mathrm{C} 20: 0$ & 0.67 & 304.470 \\
\hline linoleic acid & $\mathrm{C} 18: 2$ & 1.80 & 294.48 \\
\hline linolenic acid & $\mathrm{C} 18: 3$ & 1.05 & 278.43 \\
\hline Lignoceric acid & $\mathrm{C} 24: 1$ & 0.22 & 368.63 \\
\hline
\end{tabular}

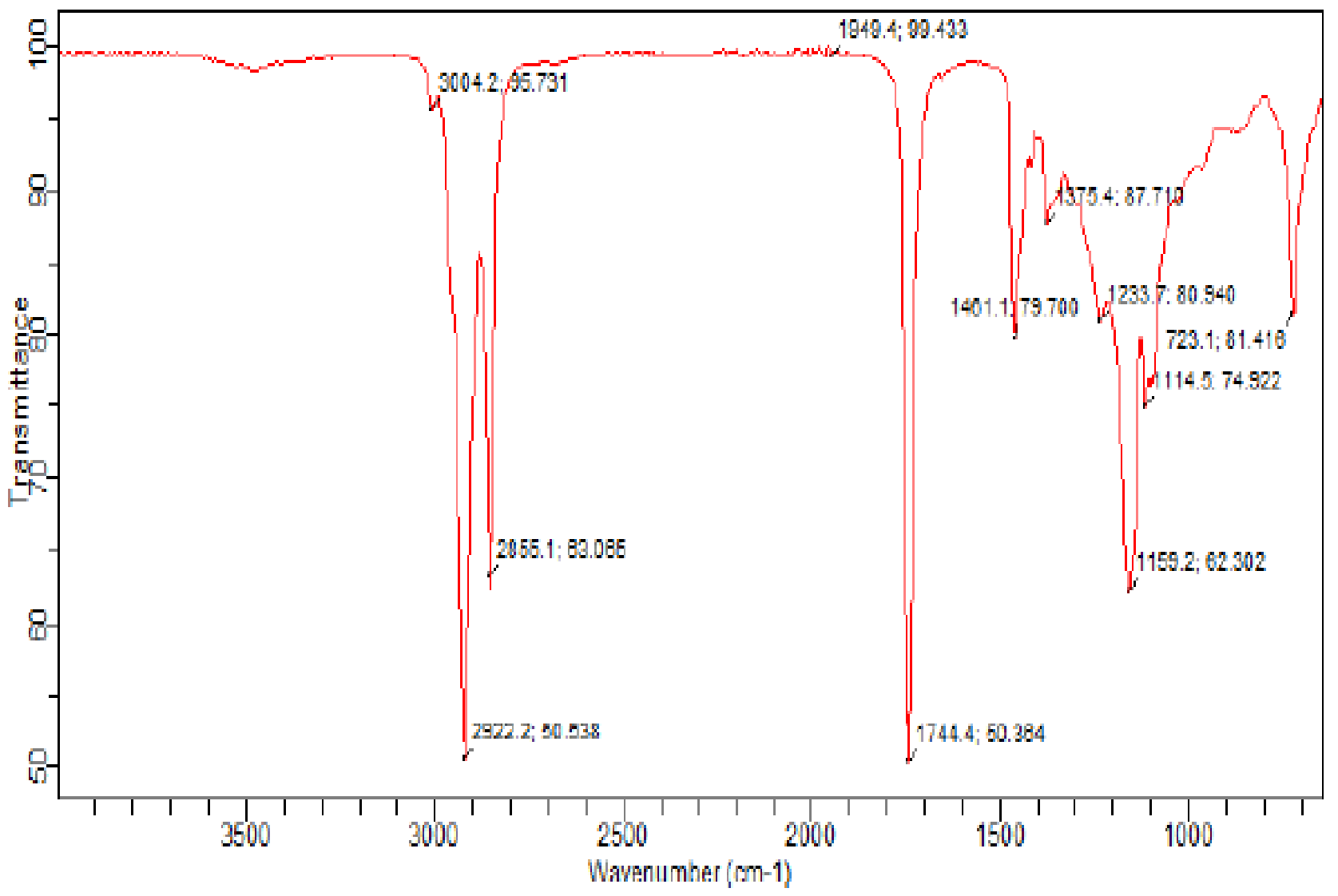

Figure 2: FT-IR spectra of used soya oil.

\subsection{Fuel Properties of the FAME Produced}

The summary of the fuel properties studied in the course of this research work is as given in table 3 . The density and kinematic viscosity of the USOFAME, $863 \mathrm{~kg} / \mathrm{m} 3$ and $4.60 \mathrm{~mm} 2 / \mathrm{s}$ which are within the ASTM limits are higher than those of the USO, $962 \mathrm{~kg} / \mathrm{m} 3$ and $47.78 \mathrm{~mm} 2 / \mathrm{s}$. High viscosity of the fuel results in poor atomization, incomplete combustion which leads to coking of injector tips and engine power loss. Low-viscosity fuel produces a very subtle spray which cannot get into the combustion cylinder, thus forming the fuel rich zone which lead to the formation of soot [36], [37]. From the result it could be inferred that FAME from used soya oil have a good injection and atomization performance. Furthermore it will offer superior lubrication and protection for the moving parts of engine than the diesel. The flash point is a shows the degree of flammability of materials. The typical flash point of pure methyl ester is $\geq 1300 \mathrm{C}$, classifying them as "non-flammable". However, during production and purification of biodiesel, not all the methanol may be removed, making the fuel flammable and dangerous to handle and store if the flash point falls below 1300C. The flash point is $1620 \mathrm{C}$ for used soya oil fatty acid methyl ester.. This is within the ASTM standard as shown in Table 3, indicative of the 


\section{Empirical Modeling of Kinetics of Transesterification and Cold Flow Properties of Used Soya Oil Biodiesel}

safety of USOFAME in handling and storage. Cetane number serves as a measure of ignition quality of the fuel. This is the most pronounced change from vegetable oil to the transesterified product. Fuels with low cetane number show an increase in emission due to incomplete combustion. The lower limit for cetane number by ASTM standards is 51 . The values obtained for used soya oil biodiesel is 61.00.. Thus the obtained result which are within the acceptable ASTM limits indicates that the produced biodiesel possess good ignition response. The cloud point which is the lowest temperature of first appearance of wax-like material on cooling the biodiesel was determined as $00 \mathrm{C}$, and the pour point which is the lowest temperature at which the fuel will still pour was determined as $-40 \mathrm{C}$ for used soya oil biodiesel. The cold filter plugging point is the lowest temperature at which the filter is plugged such that the fuel will no longer pass through the filter was determined as $-2.80 \mathrm{C}$ in this work. The characteristics of the biodiesel produced is within the ASTM standards for biodiesel, as shown in Table 3. However the cloud and pour points might give rise to cold flow problems in cold season. This problem however could be overcome by the addition of suitable cloud and pour point depressants or by blending with diesel oil [38].

Table 3: Fuel properties of USOFAME

\begin{tabular}{|c|c|c|c|c|}
\hline Properties & Unit & USOFAME & ASTM Standards & Test Method \\
\hline Acid value & $\mathrm{mgKOH} / \mathrm{g}$ & 0.400 & 0.50 & D664 \\
\hline Density & $\mathrm{Kg} / \mathrm{m} 3$ & 863 & $860-900$ & D93 \\
\hline $\begin{array}{c}\text { Kinematic viscosity@ } \\
\text { 400C }\end{array}$ & $\mathrm{mm} 2 / \mathrm{s}$ & 4.60 & $1.9-6.0$ & D445 \\
\hline Water \& sediment & $\%$ & 0.5 & 0.5 & D2209 \\
\hline Flash point & $0 \mathrm{C}$ & 162 & $100-170$ & D93 \\
\hline Cloud point & OC & 0 & & D2500 \\
\hline Cetane number & & 61.00 & $48-65$ & D613 \\
\hline Refractive index & & 1.4710 & 1.38 & \\
\hline Specific gravity & $\mathrm{Kg} / \mathrm{m} 3$ & 0.873 & $0.860-0.900$ & \\
\hline Calorific value & $\mathrm{MJ} / \mathrm{Kg}$ & 40.28 & 42.06 & D35 \\
\hline Pour point & 0C & -4 & & D97 \\
\hline Iodine value & $\mathrm{gI} 2 / 100 \mathrm{~g}$ & 30.60 & 42.46 & D4067 \\
\hline Cold filter plugging point & OC & -2.8 & & D6371 \\
\hline
\end{tabular}

\subsection{Kinetics of transesterification of USO}

Methanolysis of used soya oil using sodium hydroxide $(\mathrm{NaOH})$ catalyst was carried out in batches at temperatures of $450 \mathrm{C}$, $550 \mathrm{C}$ and $650 \mathrm{C}$. The rate constants evaluated by solving the ODE 6 to 25 using polymath 5.1 software are as shown in table 4. From the table, it could be observed that the values of the forward rate constants, $\mathrm{k} 1, \mathrm{k} 3$, and $\mathrm{k} 5$ for transesterification of USO are greater than those of the reverse reaction $\mathrm{k} 2, \mathrm{k} 4$ and $\mathrm{k} 6$ .This shows that the forward reaction greatly exceeded the reverse reaction which could be neglected for the operating experimental conditions. This conforms with the findings of [39], [40]. who separately reported predominance of forward reaction compared with backward reaction in their report of transesterification of jatropher oil and waste sunflower oil respectively. The rate constant for conversion of triglyceride to diglyceride, $\mathrm{k} 1$ was the lowest of all the forward reaction at all reaction temperature and this step could be considered the rate limiting step (RLS). Again the rate constant for the RLS increased with increase in temperature. This shows that the rate limiting step for transesterification of USO is favored at high temperature, indicative of the fact that heat is required for the reaction. The plots of lnk versus $1 / \mathrm{T}$ of the Arrhenius equation 27 for evaluating the activation energy are given in figures 3 to 8 . The activation energies obtained from evaluation of the slopes of the plots are as given in table 4.The activation energy of the RLS for palm oil transesterification has been reported by [41], and [42] to be in the range of 27.3 to $61.5 \mathrm{KJ} / \mathrm{mol}$. The activation energy of the RLS for transesterification of USO in this work is $19.31 \mathrm{KJ} / \mathrm{mol}$. The two factors that affect the kinetics of transesterification of oil are the degree of saturation of the oil, affecting TG to DG reaction step and chain length distribution of the oil affecting MG to GL reaction step. As the degree of saturation of the soya oil is low therefore the activation energy is relatively low, showing ease of its. transesterification. 
Empirical Modeling of Kinetics of Transesterification and Cold Flow Properties of Used Soya Oil Biodiesel

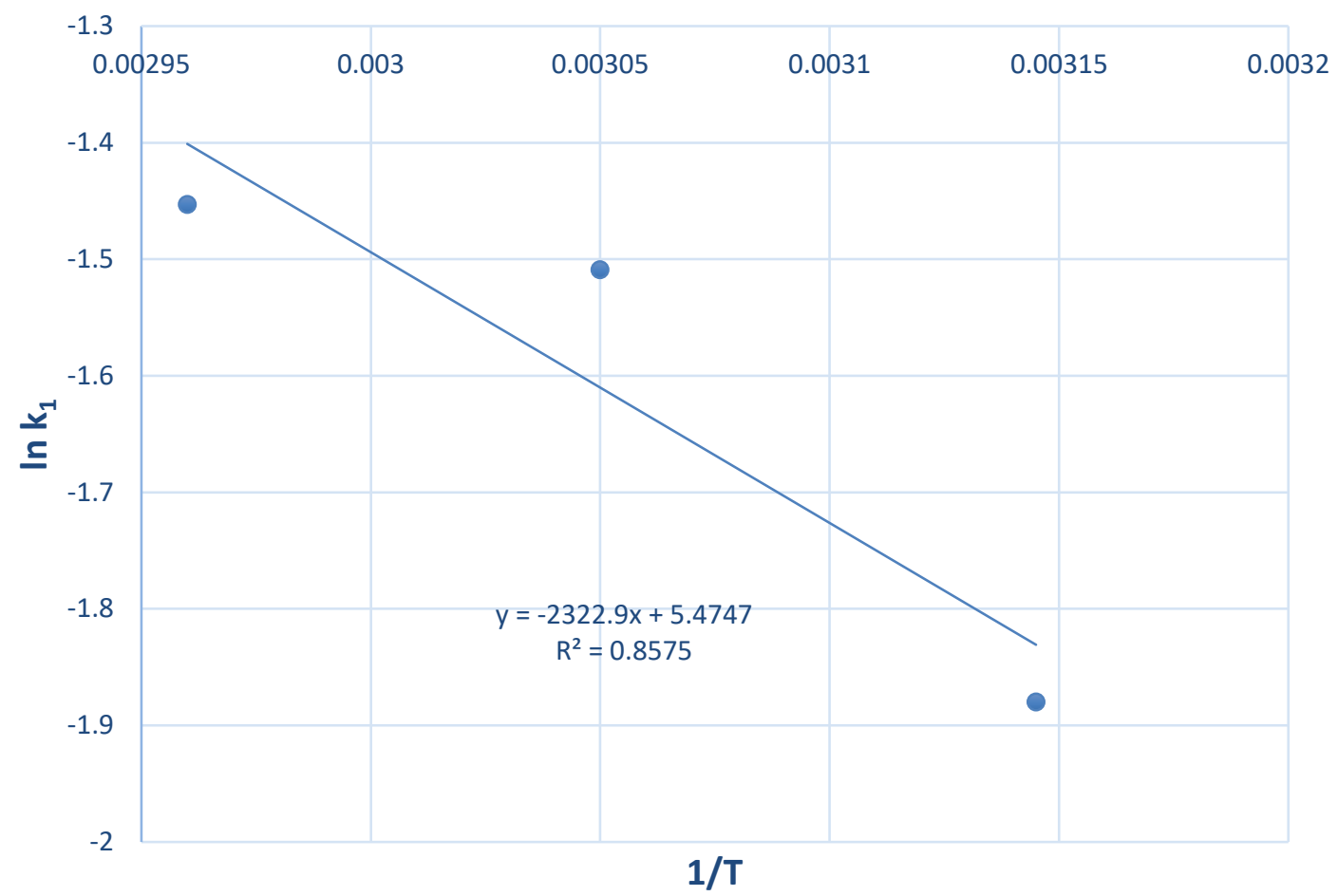

Figure 3: A plot of In K1 VS 1/T for USOFAME

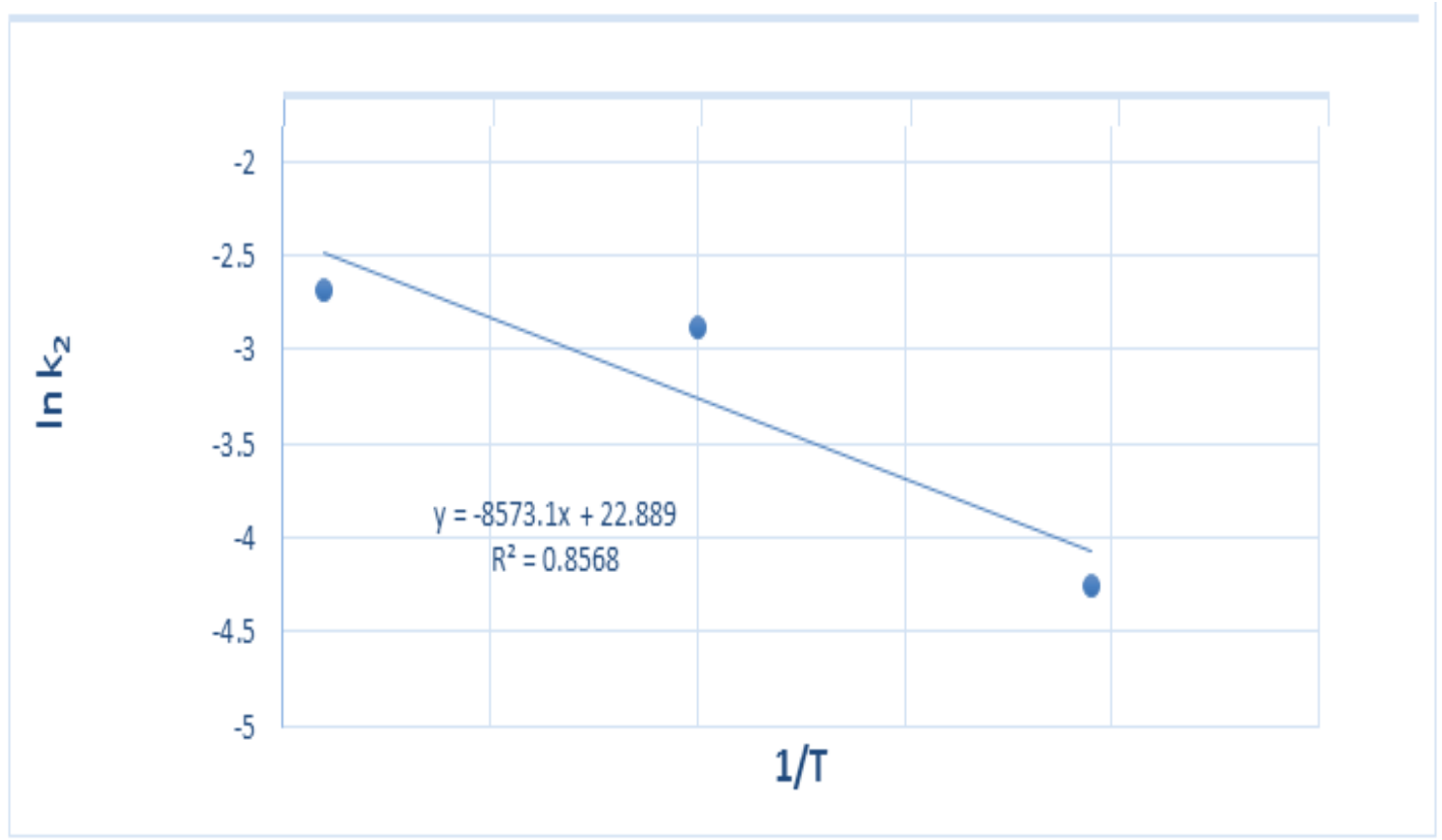

Figure 4: A plot of In 2 VS 1/T for USOFAME 
Empirical Modeling of Kinetics of Transesterification and Cold Flow Properties of Used Soya Oil Biodiesel

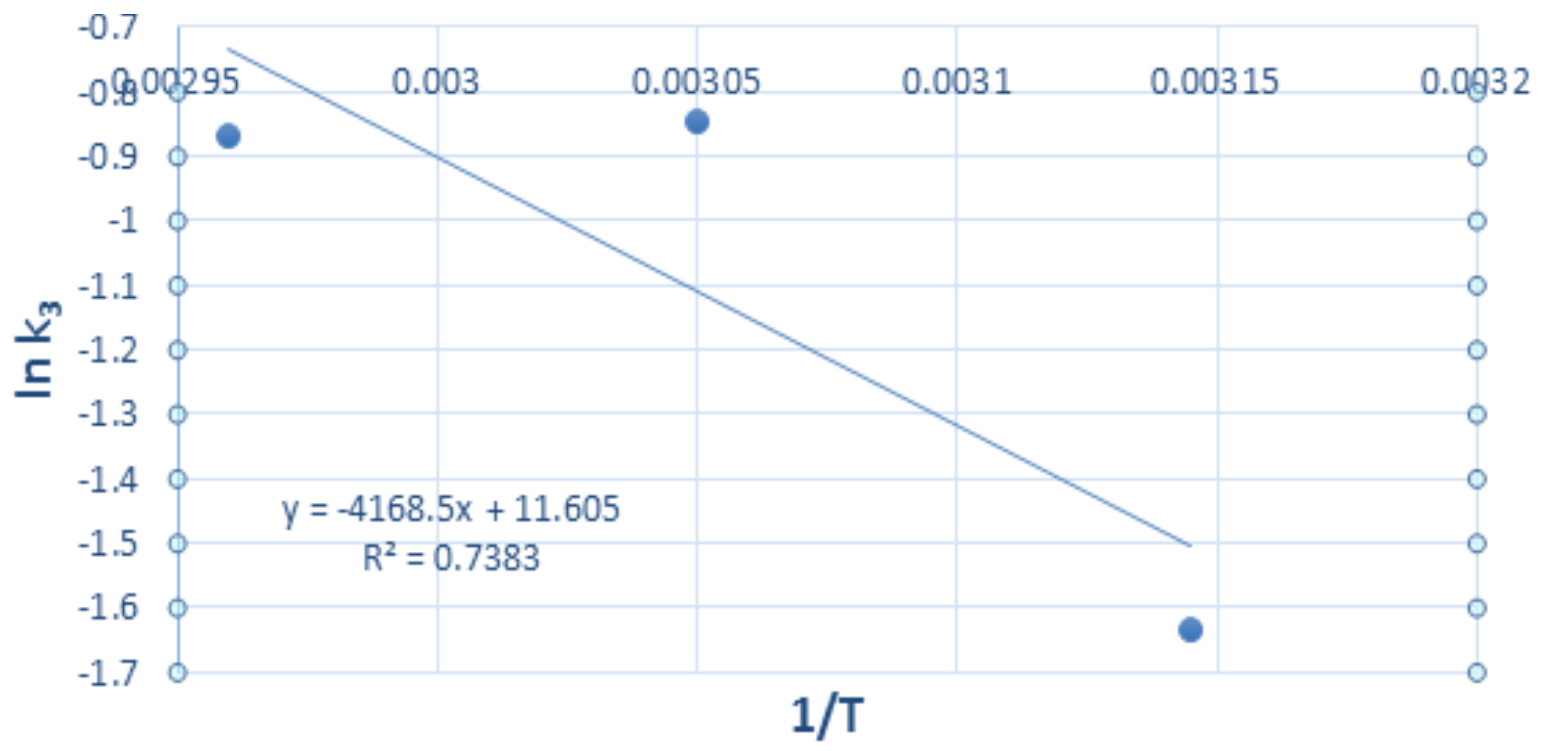

Figure 5: A plot of In K3 VS 1/T for USOFAME

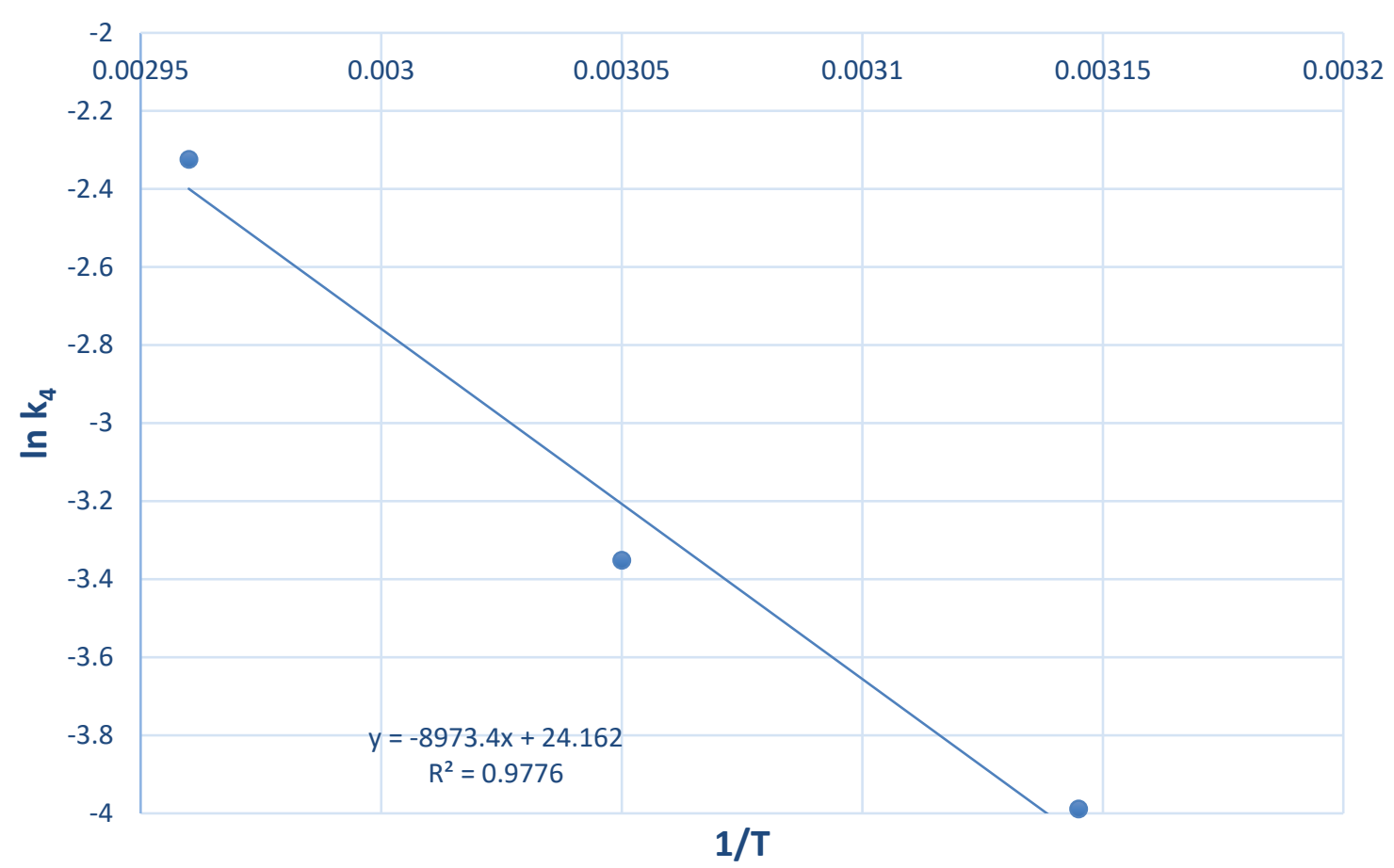

Figure 6: A plot of In K4 VS 1/T for USoFAME 
Empirical Modeling of Kinetics of Transesterification and Cold Flow Properties of Used Soya Oil Biodiesel

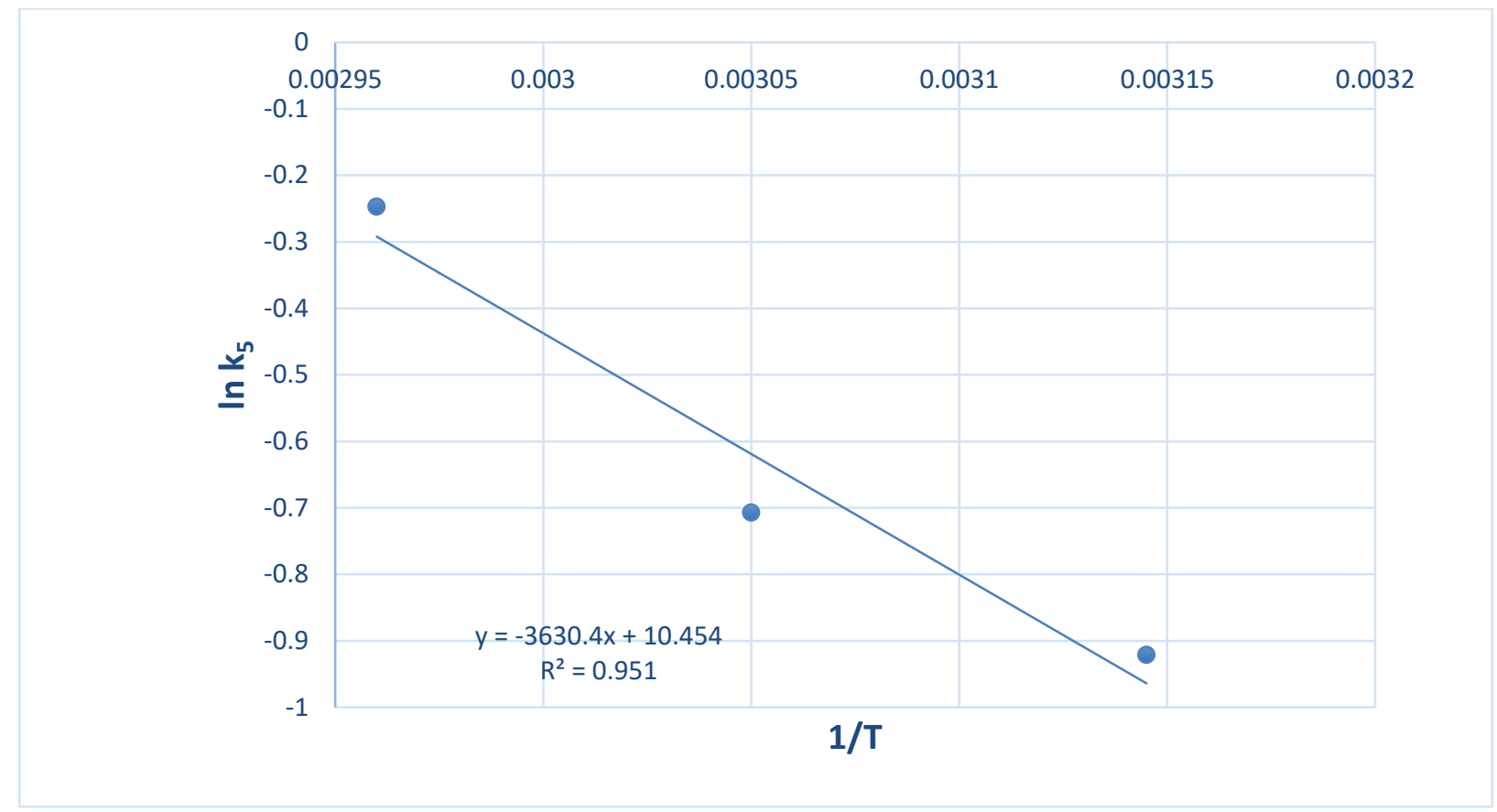

Figure 7: A plot of In K5 VS 1/T for USOFAME

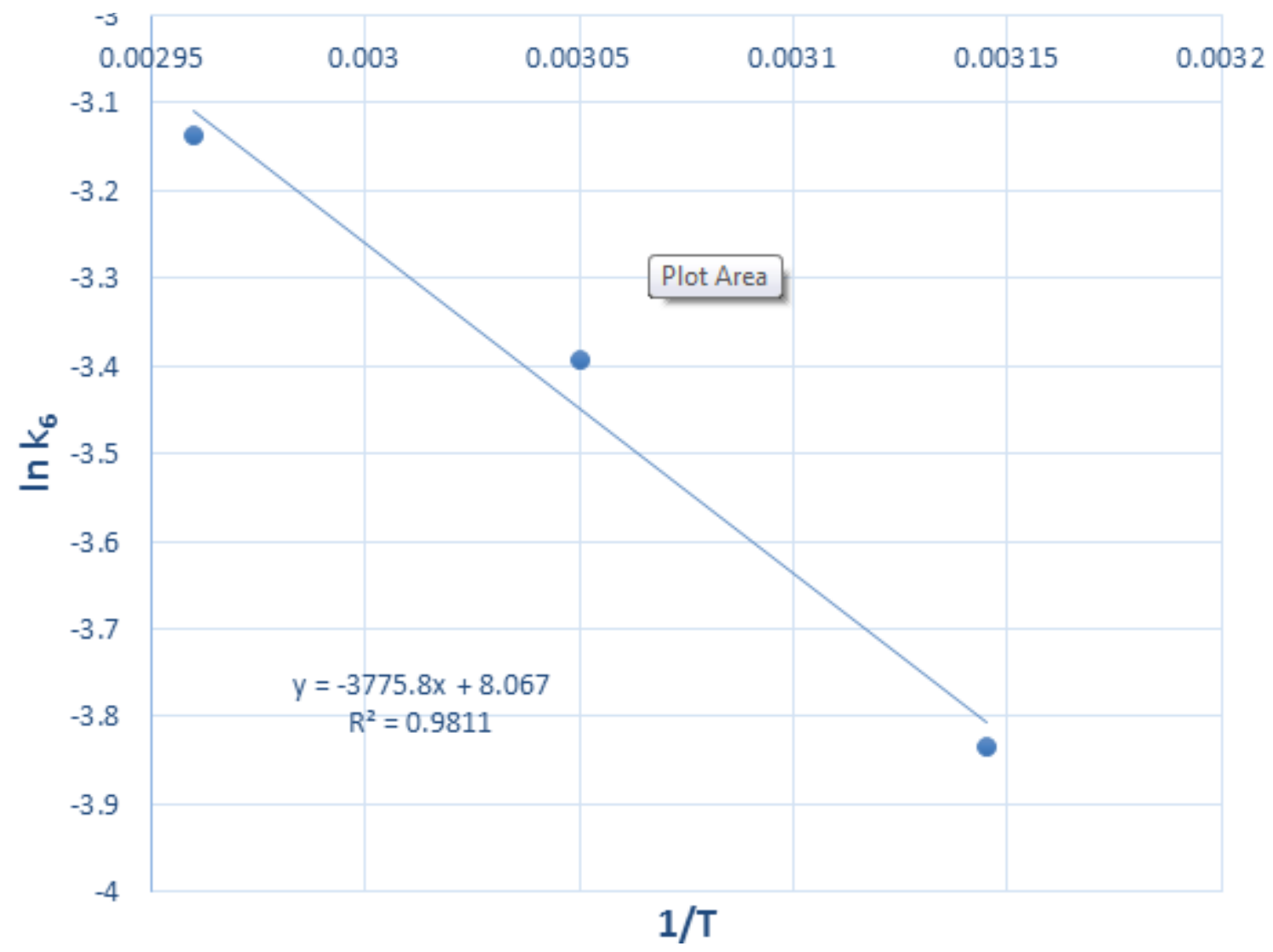

Figure 8: A plot of In K6 VS 1/T for USOFAME 
Empirical Modeling of Kinetics of Transesterification and Cold Flow Properties of Used Soya Oil Biodiesel

Table 4: Rate constants at different temperatures and activation energy for transesterification of used soya oil

\begin{tabular}{|c|c|c|c|c|}
\hline Used soya oil transesterification & & & & \\
\hline & $45 \mathrm{oC}$ & $55 \mathrm{oC}$ & $65 \mathrm{oC}$ & $\Delta E(\mathrm{~kJ} / \mathrm{mol})$ \\
\hline$k_{1}$ (min-1) & 0.165 & 0.223 & 0.234 & 19.31 \\
\hline$k_{2}$ (min-1) & 0.0142 & 0.0559 & 0.0674 & 71.280 \\
\hline$k_{3}$ (min-1) & 0.197 & 0.430 & 0.416 & 34.657 \\
\hline$k_{4}$ (min-1) & 0.0189 & 0.035 & 0.0978 & 74.604 \\
\hline$k_{5}(\min -1)$ & 0.398 & 0.493 & 0.786 & 30.183 \\
\hline$k_{6}(\min -1)$ & 0.0216 & 0.0336 & 0.0437 & 31.392 \\
\hline
\end{tabular}

Product distribution for used soya oil transesterification.

The formation of products and disappearance of reactants at temperatures of $45,55,65 \mathrm{oC}$ for transesterification of used soya oil using $\mathrm{NaOH}$ catalyst are shown in Figures 9. The figures shows that the product concentrations (BD and GL) increased with increases in reaction time while the reactants concentration (TG, DG, MG, and $\mathrm{MN}$ ) decreased with increase in reaction time. The concentration of the intermediate reactants (DG and MG) however initially increased with increase in time and later decreased with increase in time. Overall, the change in
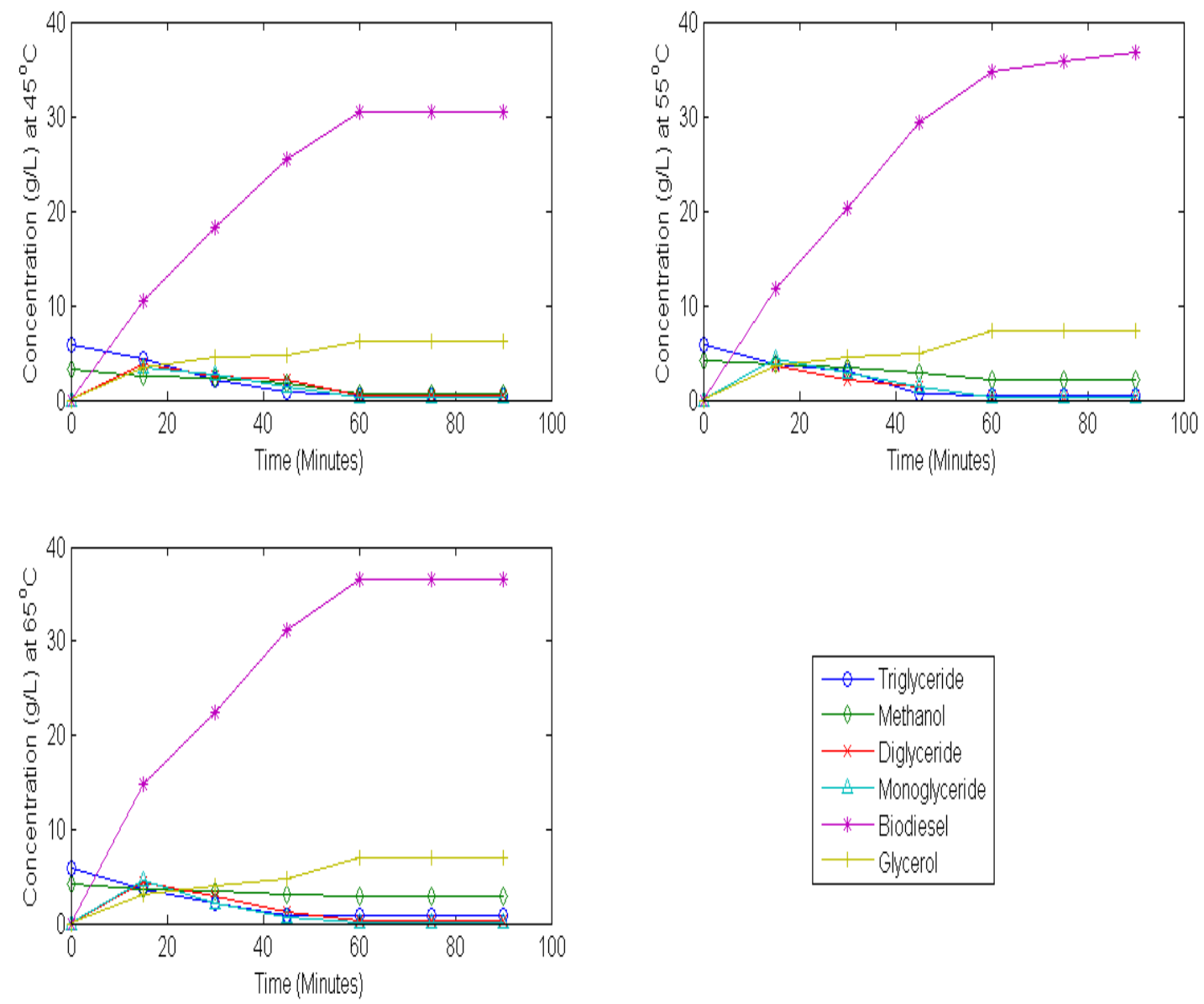

Figure 9: Product distribution for used soya oil transesterification at $45^{\circ} \mathrm{C}$

(b) at $55^{\circ} \mathrm{C}$

(c) at $65^{\circ} \mathrm{C}$. 


\section{Empirical Modeling of Kinetics of Transesterification and Cold Flow Properties of Used Soya Oil Biodiesel}

\subsection{Modeling of effect of blending on cold flow properties of USOFAME}

The cold flow properties of biodiesel are evaluated in terms of cold flow temperature operability, cloud point $(\mathrm{CP})$, cold filter plugging point (CFPP), pour point (PP) etc. The values of the cold flow properties $\mathrm{CP}$, CFPP and PP were determined experimentally for the various biodiesel fraction in the blends. The plot of variation of the cold flow temperature operability of the USOFAME mix with the biodiesel fraction is as given in figure 10. From the figure, it could be seen that the CP, CFPP and PP increased as the biodiesel fraction in the mix increased. The cloud point is of highest value while the pour point is the least. The modeling equations $2,3,4$ are fitted to data of figure 10 using least square regression of Microsoft excel. The correlation constants and the coefficient of determination of the models predicting cold flow temperature operability of the blend as a function biodiesel fraction are as given in table 5. The correlation constants are used for calculation of the cold flow properties using the modeling equation while the coefficient of determination is used to discriminate between the fitting efficiency of the models to the data. The comparison between the measured and the predicted cold flow properties using modeling equations are given in table 6-8. The model with highest coefficient of determination is adjudged the best fitting model while the model with least percentage error difference between the measured and predicted values, gave credence to the degree of efficiency of data fitting by the model. From tables 5 and 7, it could be seen that the fitting model of highest coefficient of determination and least percentage error difference is polynomial model followed closely by the linear model. The polynomial model is therefore the best fitting model for predicting $\mathrm{CP}, \mathrm{CFPP}$ and $\mathrm{PP}$ as a function of biodiesel fraction.

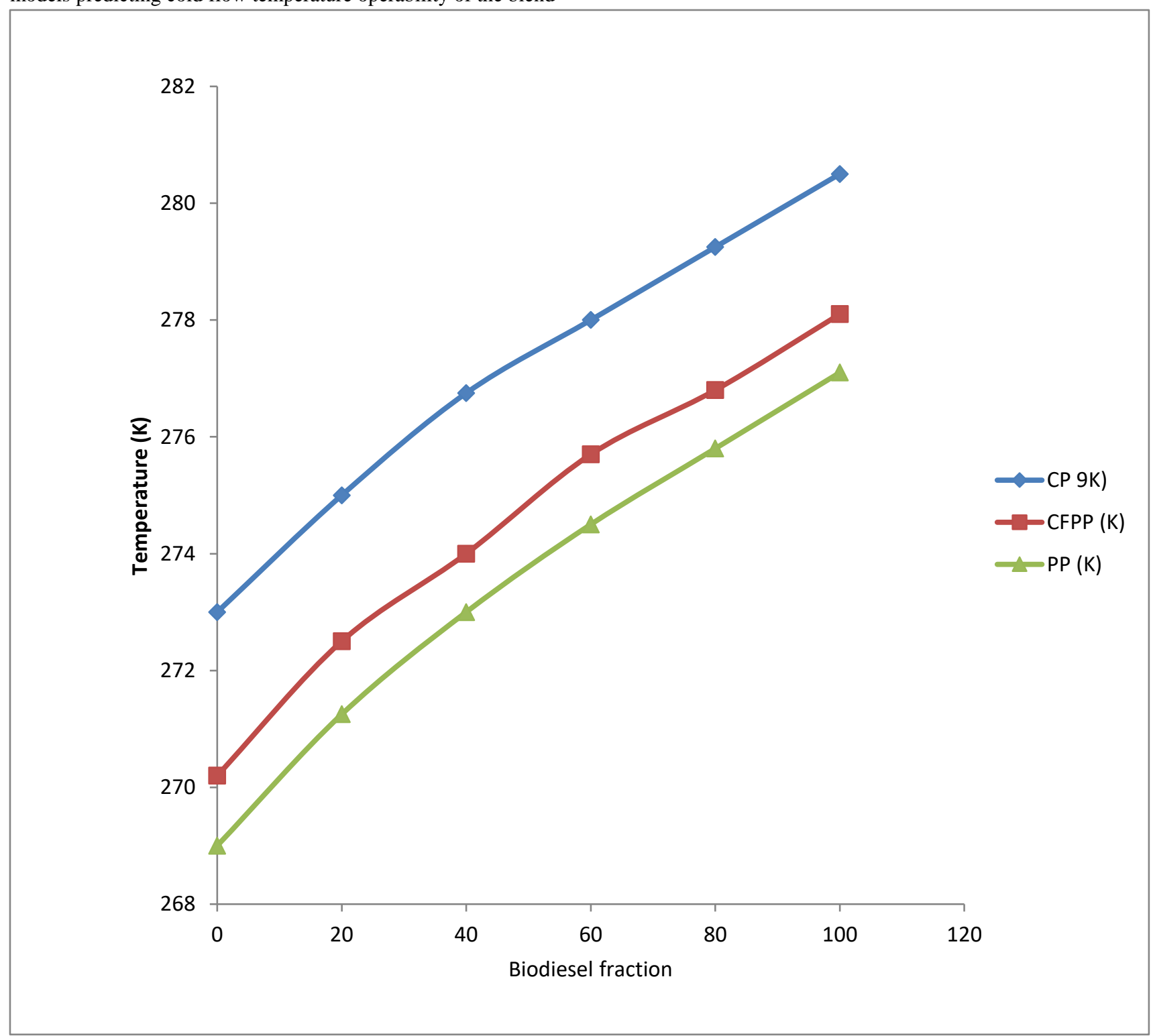

Figure 10: Effect of blending on cold flow properties of biodiesel 


\section{Empirical Modeling of Kinetics of Transesterification and Cold Flow Properties of Used Soya Oil Biodiesel}

Table 5: Correlation constants and coefficient of determination of predicting models for CP, FPP and PP

\begin{tabular}{|c|c|c|c|c|c|c|c|c|c|c|c|}
\hline \multicolumn{12}{|c|}{ Linear Model $\quad \mathrm{Y}=\mathrm{a}+\mathrm{bx}$} \\
\hline \multicolumn{4}{|l|}{$\mathrm{CP}$} & \multicolumn{4}{|l|}{ CFCP } & \multicolumn{4}{|l|}{ PP } \\
\hline $\mathrm{a}$ & $\mathrm{B}$ & $\mathrm{R} 2$ & & $\mathrm{a}$ & $\mathrm{b}$ & $\mathrm{R} 2$ & & $\mathrm{a}$ & B & $\mathrm{R} 2$ & \\
\hline 273.5 & 0.072 & 0.984 & & 270.5 & 0.078 & 0.981 & & 269.4 & 0.079 & 0.987 & \\
\hline \multicolumn{12}{|c|}{ Exponential Model $\quad \mathrm{Y}=\mathrm{c}+\mathrm{edx}$} \\
\hline \multicolumn{4}{|l|}{$\mathrm{CP}$} & \multicolumn{4}{|l|}{ CFPP } & \multicolumn{4}{|l|}{ PP } \\
\hline c & $\mathrm{D}$ & $\mathrm{R} 2$ & & $\mathrm{c}$ & $\mathrm{d}$ & $\mathrm{R} 2$ & & $\mathrm{c}$ & $\mathrm{d}$ & R2 & \\
\hline 273.5 & 0.000 & 0.983 & & 270.5 & 0.000 & 0.980 & & 269.4 & 0.000 & 0.986 & \\
\hline \multicolumn{12}{|c|}{ Polynomial Model $\quad \mathrm{Y}=\mathrm{f}+\mathrm{g}+\mathrm{hx} 2$} \\
\hline \multicolumn{4}{|l|}{$\mathrm{CP}$} & \multicolumn{4}{|l|}{ CFPP } & \multicolumn{4}{|l|}{$\mathrm{PP}$} \\
\hline$f$ & $\mathrm{G}$ & $\mathrm{H}$ & R2 & $\mathrm{f}$ & $\mathrm{g}$ & $\mathrm{H}$ & R2 & $\mathrm{f}$ & $\mathrm{g}$ & $\mathrm{H}$ & R2 \\
\hline 273.1 & 0.099 & 0.000 & 0.996 & 270.2 & 0.106 & 0.000 & 0.998 & 260.9 & 0.108 & 0.000 & 0.999 \\
\hline
\end{tabular}

Table 6: Comparison between measured and predicted CP, CFPP, and PP using linear model

\begin{tabular}{|l|l|l|l|l|l|l|l|l|l|}
\hline BF & $\begin{array}{l}\text { Meas. } \\
\text { CP }\end{array}$ & $\begin{array}{l}\text { Pred. } \\
\text { CP }\end{array}$ & Perc. Deff. & $\begin{array}{l}\text { Meas. } \\
\text { CFPP } \\
\text { CFPP }\end{array}$ & $\begin{array}{l}\text { Pred. } \\
\text { Diff. }\end{array}$ & $\begin{array}{l}\text { Meas. } \\
\text { PP }\end{array}$ & $\begin{array}{l}\text { Pred. } \\
\text { PP }\end{array}$ \\
\hline 0 & 273.00 & 273.00 & 0.00 & 270.20 & 270.15 & -0.02 & 269.00 & 269.40 & 0.15 \\
\hline 20 & 275.30 & 274.94 & -0.13 & 272.50 & 272.06 & -0.16 & 271.25 & 270.98 & -0.10 \\
\hline 40 & 276.15 & 275.88 & -0.10 & 274.00 & 273.38 & -0.23 & 273.00 & 272.56 & -0.16 \\
\hline 60 & 278.00 & 277.82 & -0.19 & 275.70 & 274.82 & 0.32 & 274.50 & 274.14 & -0.33 \\
\hline 80 & 279.25 & 279.26 & -0.01 & 276.81 & 276.74 & -0.02 & 275.80 & 275.72 & -0.03 \\
\hline 100 & 280.50 & 280.70 & 0.07 & 278.10 & 277.70 & 0.15 & 277.10 & 277.30 & 0.07 \\
\hline
\end{tabular}

Table 7: Comparison between measured and predicted CP, CPP and PP using exponential model

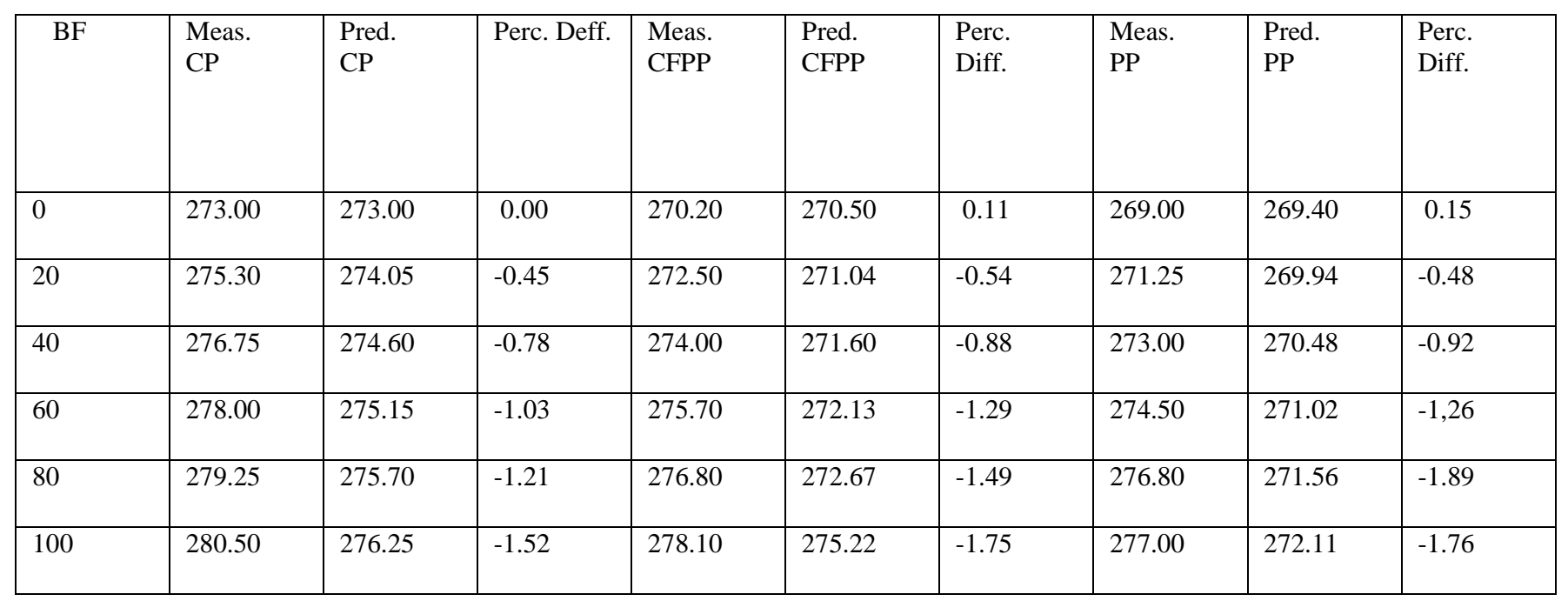


Empirical Modeling of Kinetics of Transesterification and Cold Flow Properties of Used Soya Oil Biodiesel

Table 8; Comparison between measured and predicted CP,CFPP and PP using polynomial model

\begin{tabular}{|l|l|l|l|l|l|l|l|l|l|}
\hline BF & $\begin{array}{l}\text { Meas. } \\
\text { CP }\end{array}$ & $\begin{array}{l}\text { Pred. } \\
\text { CP }\end{array}$ & $\begin{array}{l}\text { Perc. } \\
\text { Deff. }\end{array}$ & $\begin{array}{l}\text { Meas. } \\
\text { CFPP }\end{array}$ & $\begin{array}{l}\text { Pred. } \\
\text { CFPP }\end{array}$ & $\begin{array}{l}\text { Perc. } \\
\text { Diff. }\end{array}$ & $\begin{array}{l}\text { Meas. } \\
\text { PP }\end{array}$ & $\begin{array}{l}\text { Pred. } \\
\text { PP } \\
\text { Diff. }\end{array}$ \\
\hline 0 & 273.00 & 273.10 & 0.04 & 270.20 & 270.20 & 0.00 & 269.00 & 269.00 & 0.00 \\
\hline 20 & 275.30 & 275.08 & -0.08 & 272.50 & 272.32 & -0.07 & 271.25 & 271.16 & -0.03 \\
\hline 40 & 276.75 & 277.06 & -0.11 & 274.00 & 274.44 & 0.16 & 273.00 & 273.32 & 0.12 \\
\hline 60 & 278.00 & 279.04 & 0.39 & 275.70 & 276.56 & -0.31 & 274.50 & 275.48 & 0.36 \\
\hline 80 & 279.25 & 280.02 & 0.28 & 276.80 & 278.68 & 0.68 & 275.80 & 277.64 & 0.66 \\
\hline 100 & 280.50 & 283.00 & 0.89 & 278.10 & 280.08 & 0.71 & 277.10 & 279.98 & 1.04 \\
\hline
\end{tabular}

Legends: $\mathrm{BF}=$ biodiesel fraction, Meas.=measured, Perc. Deff. =percentage difference, Pred. =predicted

\section{CONCLUSION}

Kinetic modeling of transeserification of USO provided data for detailed experimental design of of transesterification of the oil such as activation energy at different temperatures, forward and reverse rate constants, $\mathrm{k} 1, \mathrm{k} 2, \mathrm{k} 3, \mathrm{k} 4, \mathrm{k} 5, \mathrm{k} 6$ and revealed the RLS as the conversion of TG to DG. Modeling of cold flow properties with biodiesel fraction gave the values of cold flow temperature operability, $\mathrm{CP}, \mathrm{CFPP}$, and $\mathrm{PP}$ for given the biodiesel fractions in the blends. Polynomial model proved the best fitting model for cold flow properties as a function of biodiesel fraction.

\section{REFERENCES}

1. Issariyakul, T., Kulkami M.G., Meher, L.C., Dalai, K.K. and Bukahshi, N.N. (2008). Biodieselproduction from mixture of canola and used cooking oil. Chemical Engineering Journal 140: 77-85.

2. Fukuda, H., Kondo, A. \& Noda, H. (2001). Biodiesel fuel production by transesterificationOf oils, Bioscience Bioengineeri Journal, 92, 405-416.

3. Lee, S and Shah, Y. T. (2013). Biofuels and Bioenergy: Processes and Technologies. CRC Press,Taylor and Francis Group,

4. 600 Broken Sound Parkway NW, Suite 300 Boca Raton,FL. ISBN 978-1-4200-8955-4. Gerpen, V.J. (2005). Biodiesel Processing and Production. Fuel Processing Technology. J.86(10) 1097-1107.

5. Gui, M., Lee, K. \& Bhatia, S. (2008). Feasibility of edible oil vs. non-edible oil vs. wasteedible oil as biodiesel feedstock. Energ 33(11): 1646-1653.

6. NanthaGopal ,K., Arindam, P. , Sumit, S. , CharanSamanchi , K. Sathyanarayanan, T.\& Elango, A. (2014). Investigation of emissionand combustion characteristics of a CI enginefueled with waste cooking oil methyl ester and diesel blends, Engineering Journal, 53, 281- 287.

7. A. Demirbas, (2009). "Progress and recent trends in biodiesel fuels". Energy Conversion andManagement 50, 14-34

8. Leung, D.Y.C. \& Guo, Y. (2010). Transesterification of meat and used frying oil:Optimization for biodiesel production. Fuel Process Technology, 87. 883-890.
9. Lu, H., Liu, Y., Zhou, H., Yang, Y., Chen, M. \& Liang, B. (2009). Production of biodieselfrom Jatropha curcas L. oil. Computer and Chemical Engineering 33(5), 1091-1096.

10. Aderemi, B.O. and Hamid, B.H. (2010). Production of Biodiesel from palm oil. NigerianSociety of Chemical Engineers Proceedings, 40, 135-143. Abuja Nigeria.

11. Younis, M. N., Saeed, M. S., Khan, S., Furqan, M. U., Khan, R. U. \& Saleem, M.(2009). Production and characterization of biodiesel, from waste and vegetable oils. Journal ofQuality and Technology Management, 5(1), 111-121.

12. Attanatho, L., Magmee, S., Jenvanitpanjakul, P. (2004).Factors affecting the synthesis of biodiesel from crude palm kernel oil. The Joint International Conference on Sustainable Energy and Environment (SSE), Hua Hin, Thailand, 1-3 December 2004.

13. Lopez, L., Bocanegra, J., Malagon-remero, D., (2015). Production of biodiesel from wastecooking oil by transesterification, Ingenieria y Universidad, 19(1), 155172.

14. Alarcon, R., Malagon-Romero, D., Ladino, A, 2017. Biodisel production from waste fryingoil, Chemical Engineering Transaction, 57, 571-576.

15. Rodriguez, D., Riesco, J., Malagon-Romero, D., (2017). Production of biodiesel from wast cooking oil and castor oil blends. Chemical Engineering Transaction, 57, 679-684.

16. Sarin, A., Arora, R., Singh, N.P., Sarin, R., Malhotra, R.K.,Kundu, K., "Effect of blend of palm, jatropher, pongama biodiesel on cloud point and pour point", Energy2009, 34, pp2016-2021.

17. Ezekannagha, C.B.,Nwabueze, H.O., Ekete , J.A. Empirical Models and Rheology of someBasic Properties of Lard Biodiesel IIIII and their Blends with Diesel fuel. Journal of EmergingTrends in Engineering and applied Sciences (JETEAS) 7(3): 149-160, 2016.

18. Ogunsuyi, H.O. (2015). Production of biodiesel using African pear (Dacryodes edulis) seed oil as feedstock. Academic Journal Biotechnology 3(5), 085-092.

19. Hanumanth, M., Hebbal, O.D. \& Navindgi, M.C. (2012). Extraction of biodiesel from vegetable oil and their 


\section{Empirical Modeling of Kinetics of Transesterification and Cold Flow Properties of Used Soya Oil Biodiesel}

comparisons; International Journal of Advanced Scientific Researchand Technology, 2(2), 2249-9954.

20. Akpan , U.G., Jimoh A. and Mohammed, A.D. (2006) Extraction, Characterization and Modification of Castor Seed Oil. Leonardo Journal of Science.

21. Freedman, B., Pryde, E.H. \& Mounts, T.L. (1999). Variables affecting the yields of fatty esters from transesterified vegetable oils, 61, 1638-1643.

22. Berchmans, H.J., \& Hirata, S. (2008). Biodiesel Production from Crude Jatropha Curcas L. Seed Oil with a High Content of Free Fatty Acids. Bioresour Technol, 99, 17161721.

23. Umeuzuegbu J.C., Ezennajiego E. E., Onukwuli O. D. Production ,Characterization andOptimization of Biodiesel from Gmelina seed oil. World Journal of Innovative Research(WJIR), 8(4) April 2020 pp74-86.

24. Lapuerta, M., Armas O. \&Fernandez, J.R. (2008). Effect of Biodiesel Fuels on diesel engineemissions. Progress in Energy and Combustion Science, 34, 198-223

25. Demirbas, A. (2003) Biodiesel Fuel from vegetable oils via catalysis and non-catalysissupercritical alcohol transesterification and other methods. Energy.Conversion Manag.. 44,2093-2109.

26. Mustapha, O.A., Adebisi, A.A., and Olanipekun, B.O. Characterization of biodiesel fromalkaline refinement of waste coocking oil. International Annals of Science, 10(2), pp16-24(2021).

27. Zahoor, U., Mohamad, A.B., and Zakaria, M. Characterization of waste palm coocking oilfor biodiesel production. International Journal of Chemical Engineering and Applications, 5(2), April 2014.

28. Sonntag, A. (2012). Reaction of fats and fatty acids. In: Balley (Eds) industrial oil and fatProducts, fourth ed. Wiley, New York USA, 99-120.

29. Ampaitepin, S., Miyuki, K. \&Tetsuo, T. (2006). Life cycle analysis of biodiesel fue production: Case study of using used cooking oil as a raw material. Kyoto, Japan. Proceeding 2nd Joint International Conference on Sustainable Energy and Environment, SEE, 2123.November 2006, Bangkok, Thailand.

30. Rashid, U. and Anwar, F. (2008). Production of Biodiesel through Optimized Alkaline Catalyzed Transesterification of Rapeseed Oil. Fuel, 87, 265 - 273.

31. John, C. (2000). Interpretation of infrared spectra, a practical approach. Encyclopedia ofanalytical chemistry, R.A. Mayers (Ed). John Wiley and Sons Ltd, Chighester, 10815-10837.

32. Isah, Y., Yousif, A.A., Feroz, K.K., Suzana, Y., Ibraheem, A. \& Soh C.(2015) Comprehensivecharacterization of napier, grass as feedstock for thermochemical conversion. Open Access Energies Journal, 8:3403-3417.

33. Shuit, S.H., Lee, K.T., Kamaruddin, A.H.\&Yusup, S. (2010). Reactive extraction and in situesterification of Jatropha curcas L seed for production of biodiesel. Fuel, 89, 520-527.

34. Saifuddin, N. \& Refai, H. (2014). Spectroscopy analysis of structural transesterification in biodiesel degradation. Research Journal of Applied Sciences, Engineering and Technology,8(9), 1149-1159.

35. Jimoh, A., Abdulkareem, A.S., Afolabi, J.O. \& Odigure Odili U.C. (2012). Production and characterization of biofuel from refined groundnut oil. 10-12.
36. Endah, M.M.P., Rachimoellah, M., Nidya, S. \& Ferdy, P. (2012). Biodiesel production from kapok seed oil (Ceiba pentandra) through the transesterification process by using Cao as catalyst, International Research Journal, 12(2),3-7.

37. Ezekwe, C. C. \& Ajiwe, V. (2014). The variations of physiochemical properties of biodiesel blends with the blend ratios. International Journal of Science Innovations and Discoveries, 411 -14.

38. Prafulla, D. P., Veera, G. G., Harvind, K. R., Tapaswy, M. \& Shuguang, D. (2012). Biodiesel production from waste cooking oil using sulfuric acid and microwave irradiation processes.Journal of Environmental Protection, 3, 111-117.

39. Muazu, K., Mohammed-DaboI, I.A., Waziri, S.M., Ahmed, A.S., Bugaje, I.M., Zanna,U.A.S. Kinetic modeling of transesterification of Jatropher curcas seed oil using heterogeneous catalyst, Eng Technol 2(3) :87-94 (2015).

40. Klofutar, B., Golob, J., Licozar, B., Klofutar, C.,Zagar, E. Transesterification of rapeseed and waste sunflower oils: Mass transfer and kinetics in a laboratory batch reactor andin an industrial -scale reactor/separator setup. Bioresour Technol 101:3333-3344 (2020).

41. Danako, D., and Cheryan, M. Kinetics of palm oil transesterification in a batch reactor. Journal of the American Oil Chemists' Society 77(12): 1263-1267 (200).

42. Su, Y., Wang, H., and Bao, G. Transesterification kinetics of biodiesel production from palm oil. Huaxue Goncheng 38(11): 39-42 (2020). 